ECCOMAS

Proceedia
COMPDYN 2021

$8^{\text {th }}$ ECCOMAS Thematic Conference on Computational Methods in Structural Dynamics and Earthquake Engineering

M. Papadrakakis, M. Fragiadakis (eds.)

\title{
ASSESSMENT OF THE SHEAR PROPERTIES OF HDRBS UNDER DIFFERENT COMPRESSION LEVELS
}

\author{
E. Bruschi ${ }^{1}$, E. Gandelli ${ }^{1}$, C. Pettorusso ${ }^{1}$, and V. Quaglini ${ }^{1}$ \\ ${ }^{1}$ Department Architecture, Built Environment and Construction Engineering, Politecnico di Milano, \\ Piazza Leonardo da Vinci 32, 20133 Milan, Italy \\ \{eleonora.bruschi, emanuele.gandelli, carlo.pettorusso, virginio.quaglini\}@polimi.it
}

\begin{abstract}
Despite it is well known that the shear properties of High Damping Rubber Bearings (HDRBs) are affected by the instantaneous compression load developed during the seismic ground motion, only permissible variations of their design properties with frequency, temperature and ageing are prescribed in the standards while the influence of the compression level is usually disregarded.

Within this framework, this research addresses this drawback through both experimental and numerical investigations. In the first part of the study, small scale laminated isolators are tested on a custom biaxial machine in order to assess the secant modulus, and damping factor of the elastomeric compound under different compression levels. In the second part, the same phenomenon is investigated through cyclic shear tests on full scale HDRBs under three different levels of axial load. In the last part, a 3D finite element model of the isolator is eventually formulated in Abaqus FEM software. The mechanical response of the elastomer is simulated by means of a hyperelastic strain energy function combined with a relaxation function.

The experimental results highlight the substantial influence of the axial load on the damping capacity of the elastomer, while the shear modulus is less affected. The numerical analyses demonstrate that the vertical - horizontal coupled response of HDRBs can be accurately predicted, within the proposed formulation, with constitutive parameters estimated from simple uniaxial tests.
\end{abstract}

Keywords: High Damping Rubber Bearings, shear modulus, equivalent viscous damping, axial load, experiments, numerical model.

ISSN:2623-3347 @ 2021 The Authors. Published by Eccomas Proceedia.

Peer-review under responsibility of the organizing committee of COMPDYN 2021.

doi: $10.7712 / 120121.8712 .20758$ 


\section{INTRODUCTION}

Base isolation is today a viable solution to mitigate the effects of earthquakes on constructions. The design of the base isolation hardware necessary to implement such strategy, such as elastomeric isolators and sliding bearings, has been developed in the past decades by many researchers and is today regulated by standards.

Rubber bearings have been used as seismic isolators since the mid of the '70s [1]. Today the most popular types of rubber isolators are the High Damping Rubber Bearings (HDRBs) and the Lead Rubber Bearings (LRBs). The mechanical characteristics of HDRBs affecting their performance as seismic isolators, namely stiffness and damping, depend only on the mechanical properties of the rubber compound. On the contrary, in LRBs the elastomer is required to provide the horizontal stiffness to the isolation system as well as a certain restoring capability, while the damping capacity relies on the hysteretic deformation of the lead core. A large variety of elastomeric compounds based on either natural or synthetic rubber is nowadays available for HDRBs and LRBs, with different damping, shear modulus, and vulcanization profile, according to proprietary techniques developed by the manufacturers.

An accurate characterization of the mechanical properties of the elastomer is fundamental for the design of HDRBs and LRBs. Nevertheless, despite of the large diffusion of these devices, some shaded areas still exist that need further investigation. One issue is the dependency of the mechanical properties on the environment [2]. To date, a large part of the studies on the behaviour of rubber for bridge bearings focused on their ageing deterioration [3]. However, the mechanical properties of elastomers can change due to a number of factors other than ageing, such as the strain amplitude, the frequency of loading, the number of cycles, and air temperature variations, and the response of a structure seismically isolated with rubber bearings can be strongly influenced by each of the above parameters [4].

According to the European Standard on anti-seismic devices [5], two sets of design properties must be determined for elastomeric isolators, the Upper Bound Design Properties (UBDP) leading to the maximum forces in the superstructure, and the Lower Bound Design Properties (LBDP) leading to the maximum displacements of the isolation system. Both UBDP and LBDP should be derived from tests performed on full scale devices, but for HDRBs the Standard allows to determine the effects of temperature, frequency and ageing by testing rubber specimens under pure shear, instead of full isolators, as it is acknowledged that the cyclic behaviour of steel reinforced rubber bearings is primarily governed by the mechanical properties of rubber [6]. An important factor that is generally ignored when testing rubber specimens is the influence of the compression stress on the shear properties of the elastomer, which was instead demonstrated to have a fundamental importance and needs to be taken into account for a correct understanding of the behaviour of HDRBs under service conditions [7].

One of the first studies addressing this topic was published by Aiken [8], who tested HDRBs with shape factors (ratio of load area to stress-free area of a single rubber layer) of 8.75 and 20 and design axial stresses of 3.2 and 5,1 MPa, respectively. The bearings were tested at several levels of compression stress, from 0 to $10 \mathrm{MPa}$ for the first geometry and from 0 to $15 \mathrm{MPa}$ for the second geometry, and the results showed an increase of both shear stiffness and damping with the compression load. Kelly [9] evaluated the performance of a rubber isolator characterized by nominal shear modulus of $0.86 \mathrm{MPa}$, damping of $15 \%$ and shape factor of 30 . The compression stress was increased from 0 to $10.34 \mathrm{MPa}$, and the tests showed a negligible influence on the shear stiffness, while the damping increased from $13 \%$ to $17 \%$ (relative change of $30 \%)$.

Mori [10] tested five isolators differing for geometry and rubber mixture. When the axial load was small in comparison with the design value (say 34\%), then the shear hysteresis loop 
was a different shape from that one under the high applied axial load. Also, the area of the hysteresis loops became larger (i.e. damping increased) as the axial load was increased. On the contrary the influence of the axial load within the range between 0.68 and 1.25 times the design value on the shear stiffness was negligible. Iizuka [11] tested laminated elastomeric bearings with shape factor 20 under four different levels of compression $(0 ; 4.90 ; 9.81 ; 19.60 \mathrm{MPa})$ up to $500 \%$ shear strain. The study confirmed the influence of the axial load on the nonlinear largedeformation shear behaviour of rubber, resulting in strain-hardening in the shear direction under small axial forces, but decrease in horizontal stiffness under large axial forces probably due to buckling of the rubber layers. Ryan [12] studied the behaviour of HDRBs with design axial stress of $3.2 \mathrm{MPa}$ and shape factor of 8.27 and 20 respectively, subjected to the combined action of compression and shear force, concluding that in the range 0 to $10 \mathrm{MPa}$ the shear stiffness of HDRBs decreases with increasing of the axial load.

From the review of the above literature it is clear that, though the influence of the axial load on the shear properties of HDRBs is a fact, the sensitivity of the individual bearing can vary significantly depending on the type and amount of fillers and by the amount of cross-linking of the mixture [13].

The paper presents some approaches for investigating the influence of the axial load on the shear properties of HDRBs from both an experimental and a numerical perspective. All the studies are performed on the same natural rubber compound. In the first part of the study, small scale prototypes of HDRBs are tested under varying axial load in the range of 0.5 to about 21 $\mathrm{MPa}$, whereas in the second part the tests are performed on real scale isolators, and some experimental issues are put in evidence. Eventually, a numerical analysis is performed by using as case study the elastomeric isolator tested at full scale.

\section{SMALL SCALE PROTOTYPES}

\subsection{Test pieces}

Small circular test pieces (Fig. 1), with diameter $\boldsymbol{D}=80 \mathrm{~mm}$, are used. Every piece includes 10 rubber layers, $4 \mathrm{~mm}$ in thickness each, alternated to $2 \mathrm{~mm}$ thick steel plates. The upper and the lower rubber layers are vulcanized to two thick $(10 \mathrm{~mm})$ steel plates that fit recessing holes in the plates of the testing machine. The test pieces are made of commercial rubber compound, categorized as "Normal" (hardness between 55 and 65 International Rubber Hardness Degree (IRHD)), with shear modulus $\mathrm{G}=0.75 \mathrm{MPa}$ and equivalent viscous damping factor $\xi=$ $12 \%$.The total thickness of rubber, which is the parameter that governs the maximum shear displacement, is $40 \mathrm{~mm}$, while the primary and the secondary shape factors are $\boldsymbol{S}_{\mathbf{1}}=5$ and $\boldsymbol{S}_{\mathbf{2}}$ $=2$, respectively. $\boldsymbol{S}_{\mathbf{1}}$ is defined as the ratio of the compressed area of the rubber layer divided by the area of lateral surface free to bulge, while $\boldsymbol{S}_{2}$ is the aspect ratio, i.e. the bearing diameter divided by the total rubber thickness [14].
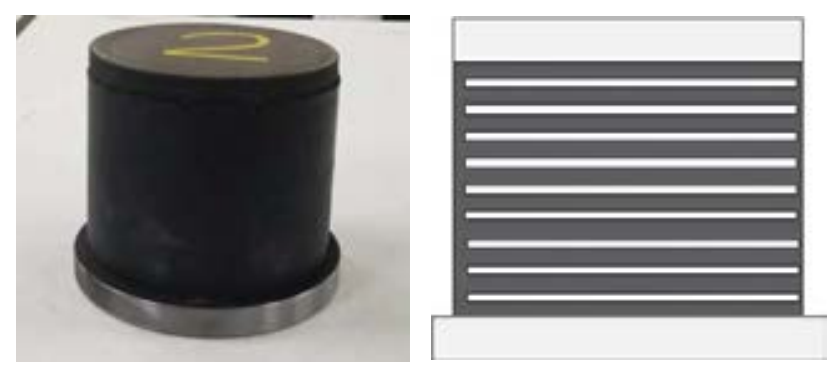

Figure 1: Small scale HDRB test piece: picture of a specimen (left), and cross-section (right). 


\subsection{Test set-up}

The biaxial testing system is illustrated in Fig. 2-left. The system consists of a stiff four columns steel frame equipped with two servo-hydraulic jacks. The vertical jack, rated $500 \mathrm{kN}$, applies the compressive load to the test piece, while the horizontal jack, rated $100 \mathrm{kN}$ and with a $100 \mathrm{~mm}$ stroke, drives a shear plate that moves horizontally. The system permits to test simultaneously a pair of test pieces, placed symmetrically with respect to the shear plate in a double shear configuration (Fig. 2-right).
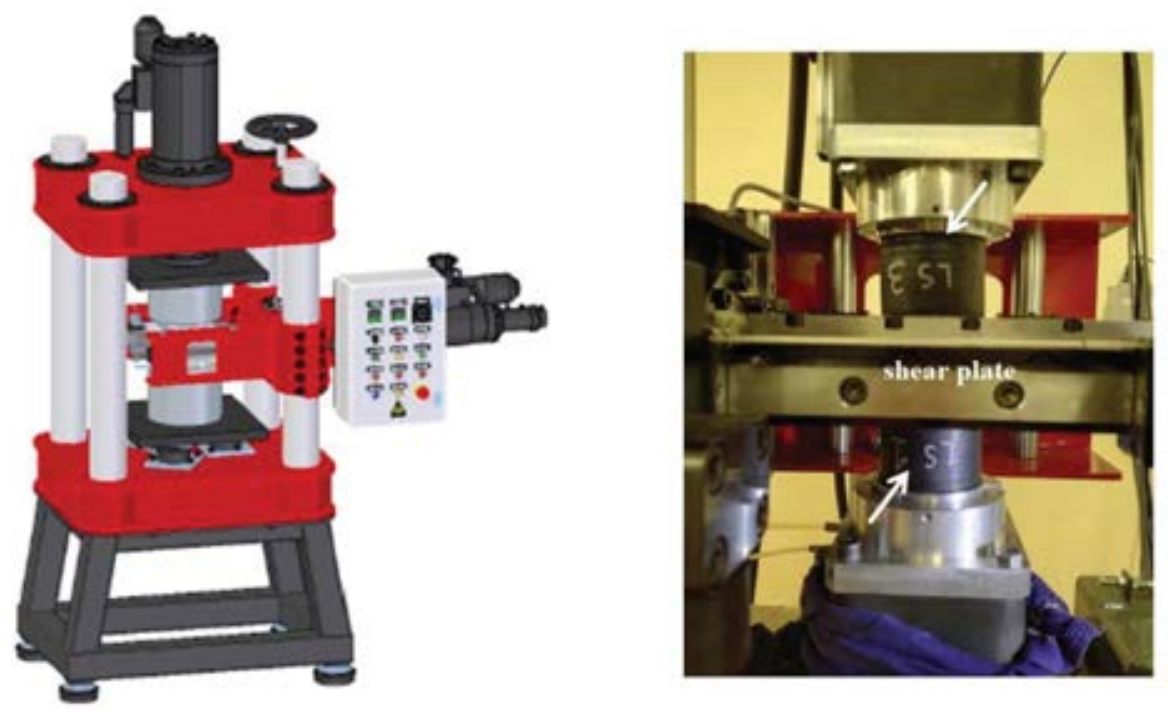

Figure 2: Schematic view of the biaxial test set-up (left), and test pieces in double shear configuration (right).

\subsection{Test procedure}

The sequence of tests performed on the pair of HDRB test pieces is outlined in Table 1. By adjusting the vertical load, the compression stress $\boldsymbol{p}$ is varied from a minimum value of 0.1 $\mathrm{MPa}$ to a maximum value of $24 \mathrm{MPa}$, with $3 \mathrm{MPa}$ increments up to $12 \mathrm{MPa}$, and $6 \mathrm{MPa}$ increments above $12 \mathrm{MPa}$. At each stress level, five full cycles of horizontal displacement are imposed with sinusoidal waveform, frequency $\boldsymbol{f}=0.5 \mathrm{~Hz}$ and amplitude $40 \mathrm{~mm}$, resulting in a shear strain amplitude $\gamma_{\boldsymbol{a}}=100 \%$. The sequence of tests is carried out in order of increasing vertical loads, with a dwell time of 30 minutes between any pair of tests in order to allow the viscoelastic recovery of the rubber. The tests are performed at a room temperature of $19 \pm 2^{\circ} \mathrm{C}$.

\begin{tabular}{clll}
\hline$p(\mathrm{MPa})$ & $\gamma_{a}(\%)$ & $f(\mathrm{~Hz})$ & cycles \\
\hline $0.1-3-6-9$ & 100 & 0.5 & 5 \\
$-12-18-24$ & 100 & & \\
\hline
\end{tabular}

Table 1: Test protocol for small scale HDRB test pieces.

\subsection{Results}

Fig. 3 illustrates the hysteretic shear force-displacement curves obtained at different levels of pressure ; in the diagrams, only the curve relevant at the third cycle is reported for each stress level. It is evident the large difference in shape between the curve at $0.1 \mathrm{MPa}$ (i.e. virtually 
without axial load), and the curves relevant to tests at $p \geq 3 \mathrm{MPa}$, with a substantial increase of the dissipated energy (i.e., the area enclosed in the loop).

From the horizontal force $F$ and the horizontal deflection $d$ of the single specimen, the shear stress $\tau$ and shear strain $\gamma$ of rubber are calculated as follows:

$$
\begin{gathered}
\tau=\frac{F}{A} \\
\gamma=\frac{d}{t_{e}}
\end{gathered}
$$

where $\boldsymbol{A}$ is the area of the plan section of a rubber layer parallel to the direction of shear, and $\mathbf{t}_{\mathbf{e}}$ is the total thickness of rubber subjected to shear. From the hysteretic shear stress-strain diagram, the secant shear modulus $\boldsymbol{G}$ and the equivalent viscous damping factor $\boldsymbol{\xi}$ are then calculated at each cycle:

$$
\begin{aligned}
G & =\frac{\tau_{2}-\tau_{1}}{2 \cdot \gamma_{a}} \\
\xi & =\frac{E D C}{2 \pi \cdot G \gamma_{a}^{2}}
\end{aligned}
$$

where $\tau_{1}$ and $\tau_{2}$ are the stresses at the maximum shear deflections in either direction, $E D C$ is the energy dissipated per cycle and $\gamma_{a}=1$ is the shear strain amplitude.

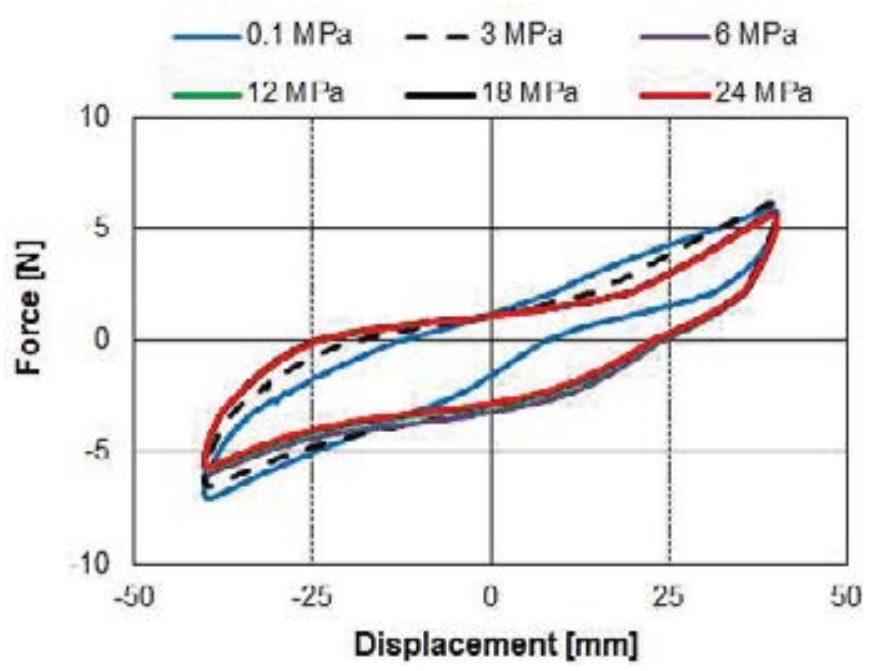

Figure 3: Shear force - displacement loops at different pressure levels.

Fig. 4 plots the change of $G$ and $\xi$ as a function of the compression stress $p$. The secant modulus has a $10 \%$ decrease when $p$ rises from $3 \mathrm{MPa}$ to $6 \mathrm{MPa}$, and holds constant for higher pressure levels. The equivalent viscous damping factor has a $38 \%$ increase when $p$ is increased from $0.1 \mathrm{MPa}$ to $3 \mathrm{MPa}$ and a further $10 \%$ increase at $p=6 \mathrm{MPa}$, and then it holds substantially stable up to $p=24 \mathrm{MPa}$. 

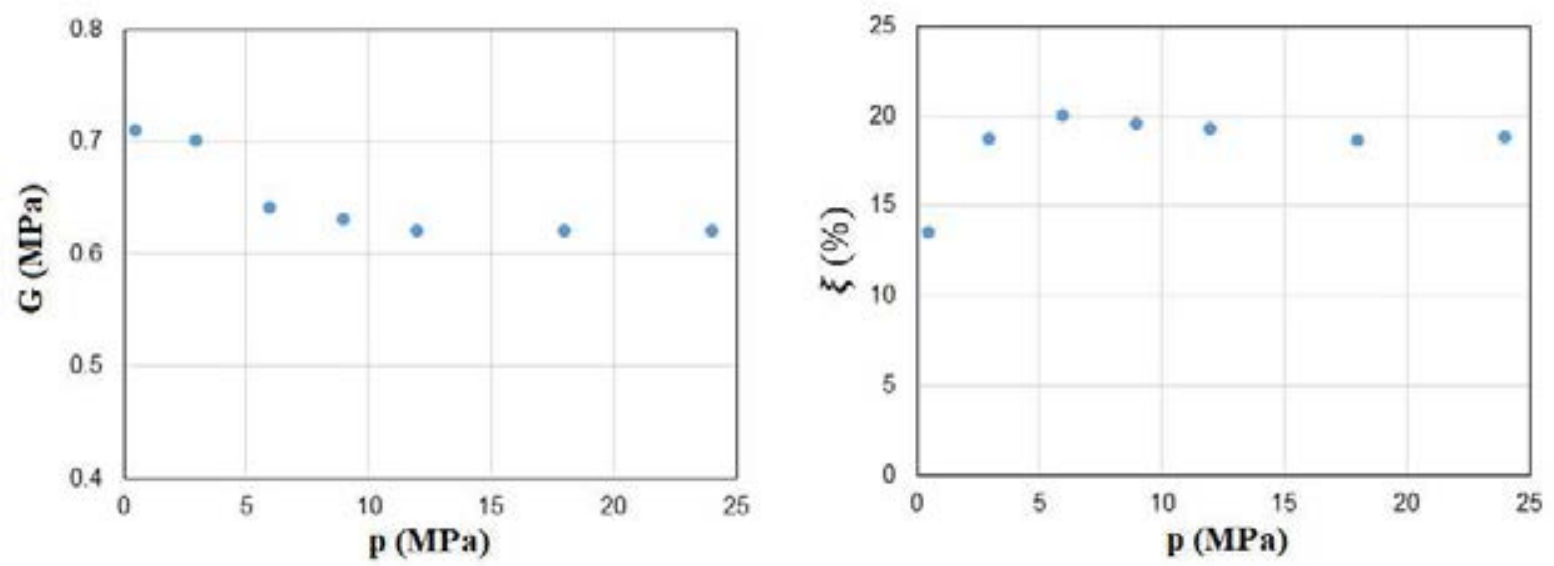

Figure 4: Influence of the compression stress on secant shear modulus (left) and equivalent viscous damping factor (right); values are determined at the third cycle.

\section{FULL SCALE ISOLATORS}

\subsection{Test pieces}

The tests pieces are two HDRBs designed for an axial load $\boldsymbol{N}_{\boldsymbol{s} \boldsymbol{d}}=1150 \mathrm{kN}$ and a seismic displacement $\boldsymbol{d}_{\boldsymbol{b} \boldsymbol{d}}=250 \mathrm{~mm}$. The devices are circular in shape, with a diameter of $500 \mathrm{~mm}$ and a total thickness of $218 \mathrm{~mm}$. Each HDRB consists of 14 rubber layers, $9 \mathrm{~mm}$ thick each, alternated with 13 steel plates, $4 \mathrm{~mm}$ thick, and 2 end plates of $20 \mathrm{~mm}$ thickness. The primary and the secondary shape factors are $\boldsymbol{S}_{\mathbf{1}}=18.9$ and $\boldsymbol{S}_{\mathbf{2}}=2$, respectively. A sketch of the cross section of the isolator is shown in Fig. 5. The raw material is the same rubber compound used to manufacture the small scale test pieces.
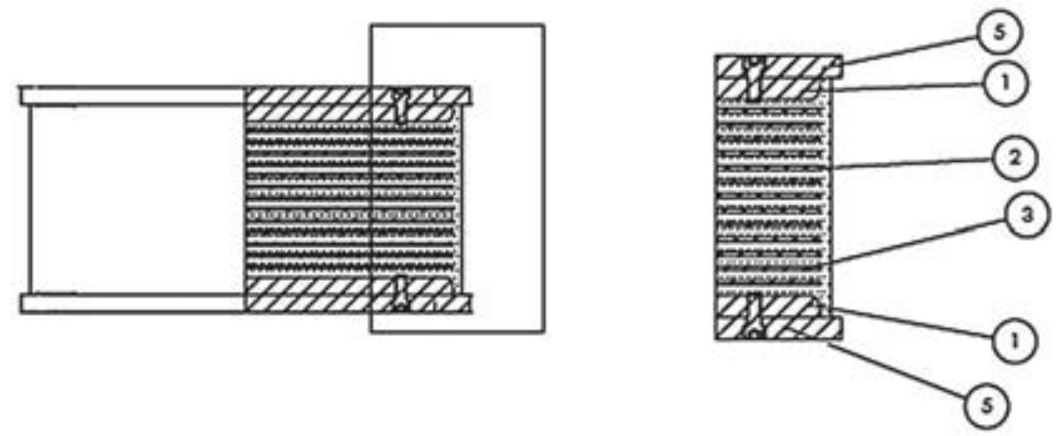

Figure 5: Sketch of the HDRD specimen, and cross-section details.

\subsection{Test set-up}

The tests were performed at the Laboratory for Testing of Materials and Structures (SisLaB) at the University of Basilicata, using a custom bearing tester system (Fig. 6). The facility has load capacity of $8000 \mathrm{kN}$ in the vertical direction and $1000 \mathrm{kN}$ in the horizontal direction, and a displacement capacity of $1000 \mathrm{~mm}$. The system incorporates a plate supported by low-friction bearings which moves in the horizontal direction, and allows to apply a shear force to the isolator. A single device can be tested each time. 


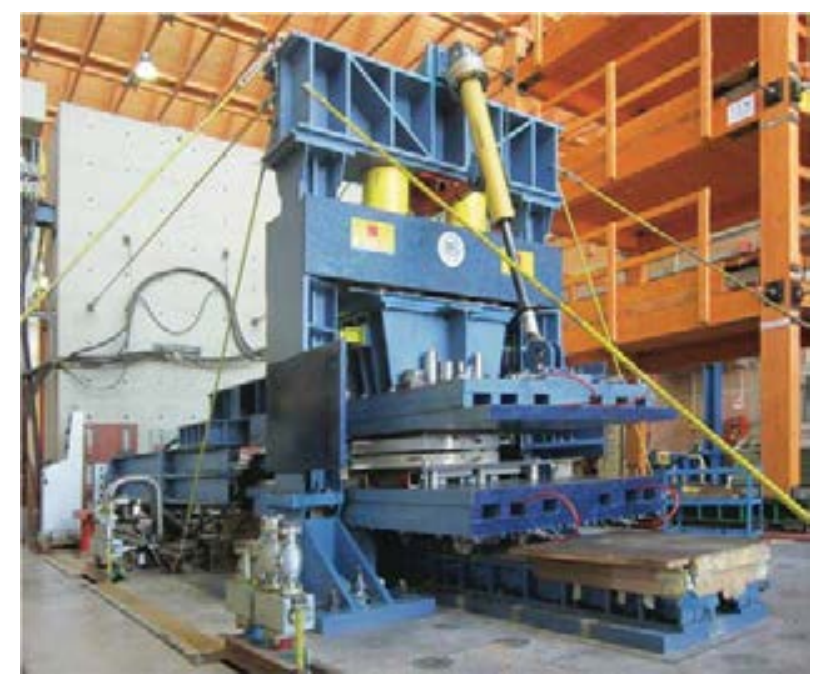

Figure 6: The bearing tester system at University of Basilicata.

\subsection{Test procedure}

The sequence of tests performed on the HDRB isolators is illustrated in Table 2. The devices are tested at $0.45,1.0$ and 2.0 times the design axial load $N_{s d}$, which correspond to a compressive stress on rubber of 2.63, 5.85 and $11.70 \mathrm{MPa}$ respectively. At each load level, three sinusoidal cycles are performed to a maximum displacement $d_{b d}=250 \mathrm{~mm}$, corresponding to a shear strain amplitude $\gamma_{a}=198 \%$, at a frequency $f=0.5 \mathrm{~Hz}$. The dwell time between two tests is of about 20 minutes. All tests are performed at room temperature.

\begin{tabular}{llll}
\hline$N(\mathrm{kN})$ & $d_{b d}(\mathrm{~mm})$ & $f(\mathrm{~Hz})$ & cycles \\
\hline 1150 & 250 & 0.5 & 3 \\
530 & 250 & 0.5 & 3 \\
2300 & 250 & 0.5 & 3 \\
\hline
\end{tabular}

Table 2: Test protocol for HDRB isolators ( $N$ : axial load; $d_{b d}$ : displacement amplitude).

\subsection{Results}

Fig. 7 illustrates the variation of the effective stiffness $k_{\text {eff }}$, evaluated at the maximum shear deflection, and the equivalent viscous damping factor $\xi$ with the axial load. The shear stiffness at $\boldsymbol{N}_{\boldsymbol{s} \boldsymbol{d}}$ is found to decrease by $9 \%$ when the axial load is halved, and to decrease by $14 \%$ when the axial load is increased by a factor of 2 . This behaviour, which is inconsistent with the findings of the small scale test, may be ascribed to the insufficient duration of the dwell time between the first and the second tests, at $1150 \mathrm{kN}$ and $530 \mathrm{kN}$ respectively, which could be too short to permit complete cooling of the isolator. Since the modulus of rubber decreases with increasing of temperature, this can explain the unexpected decay of stiffness at $0.45 \boldsymbol{N}_{\boldsymbol{s} \boldsymbol{d}}$. The equivalent viscous damping factor has a more regular behaviour, with a negligible change when the design load is halved, and a $25 \%$ increase on average when the design load is increased by a factor of 2 .

The secant modulus of the rubber can be calculated from the effective stiffness of the isolator. For a compressive stress of $5.85 \mathrm{MPa}$, corresponding to $\boldsymbol{N}_{\boldsymbol{s} \boldsymbol{d}}$, the value of the secant 
modulus derived from the tests on isolators counts $G=0.87 \mathrm{MPa}$, which is $25 \%$ higher than the value $(G=0.7 \mathrm{MPa})$ determined in the small scale tests; similarly, the equivalent viscous factor of the isolator is about $50 \%$ less than the relevant figure assessed on the small scale pieces (10.4\% against $20 \%)$.
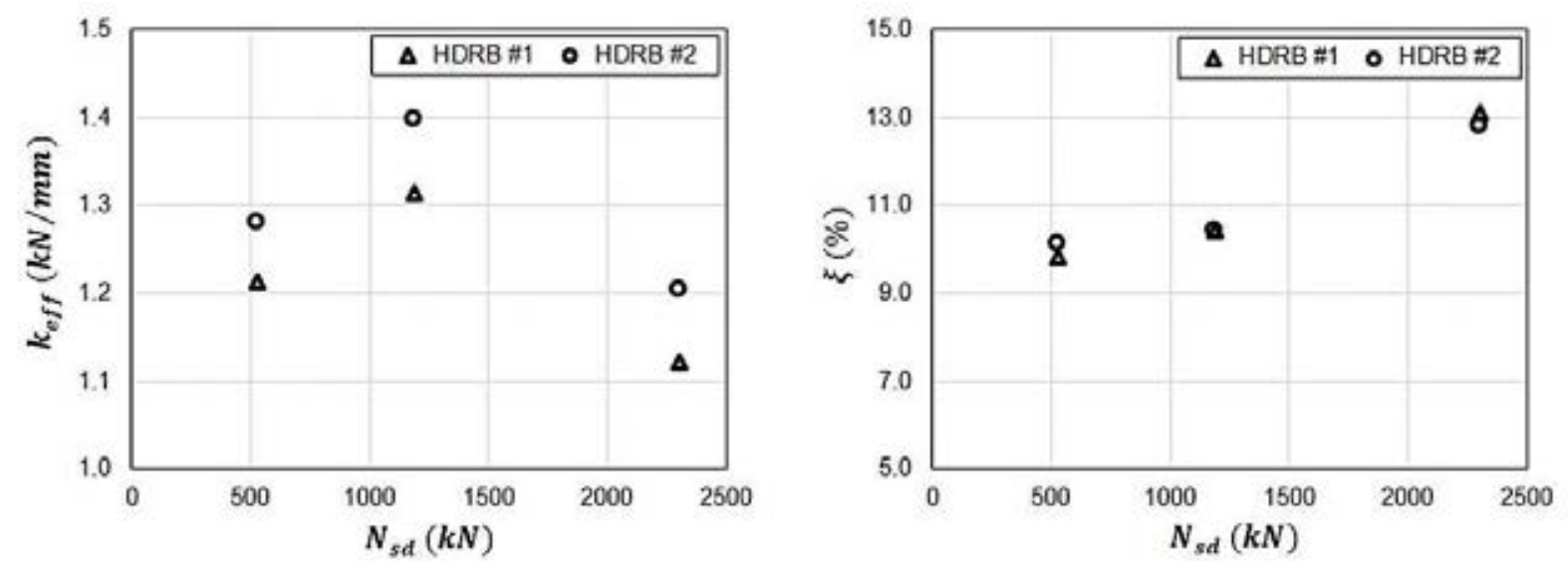

Figure 7: Influence of axial load on effective stiffness (left), and equivalent viscous damping factor (right) of full scale HDRBs; values determined at the third cycle.

\section{FINITE ELEMENT INVESTIGATION}

\subsection{Numerical formulation}

A 3D finite element model of the HDRB isolator shown in Fig. 5 has been formulated in the software program Abaqus. Taking advantage from the symmetry of the device, only half of the isolator has been modelled (Fig. 8). The size of the mesh of finite elements for the rubber layers is $10 \times 4.5 \mathrm{~mm}$. The mechanical behaviour of the elastomer has been described by using a hyperelastic constitutive law [15] to represent the force-displacement relationship, and an exponential Prony series to represent the viscous behaviour. Model parameters have been calibrated based on experimental data obtained from uniaxial tensile tests and stress relaxation tests on rubber specimens (Fig. 9), according to the procedure described by [16]. Numerical analyses have been performed by simulating the application of an axial load on the isolator, and a concurrent displacement in the horizontal direction. The horizontal displacement is applied according to a sinusoidal waveform, with amplitude $d_{b d}=250 \mathrm{~mm}$ and frequency $f=0.5 \mathrm{~Hz}$. Simulations have been performed for three values of axial load, namely $N=530 \mathrm{kN}, N=1150$ $\mathrm{kN}$, and $N=2300 \mathrm{kN}$, with 3 cycles per load level.

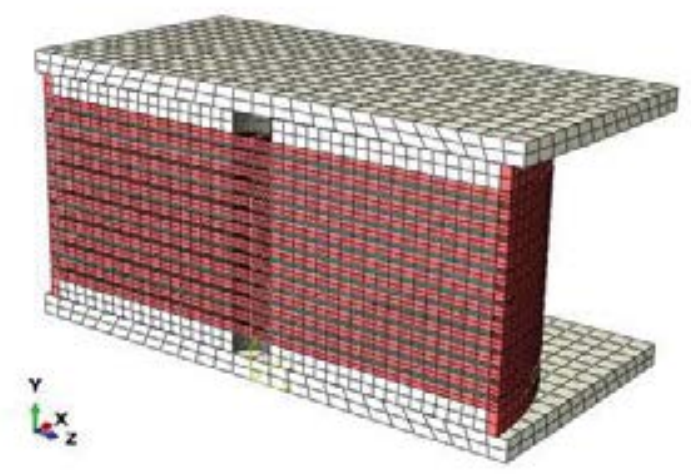

Figure 8: 3D finite element model of the HDRB isolator. 

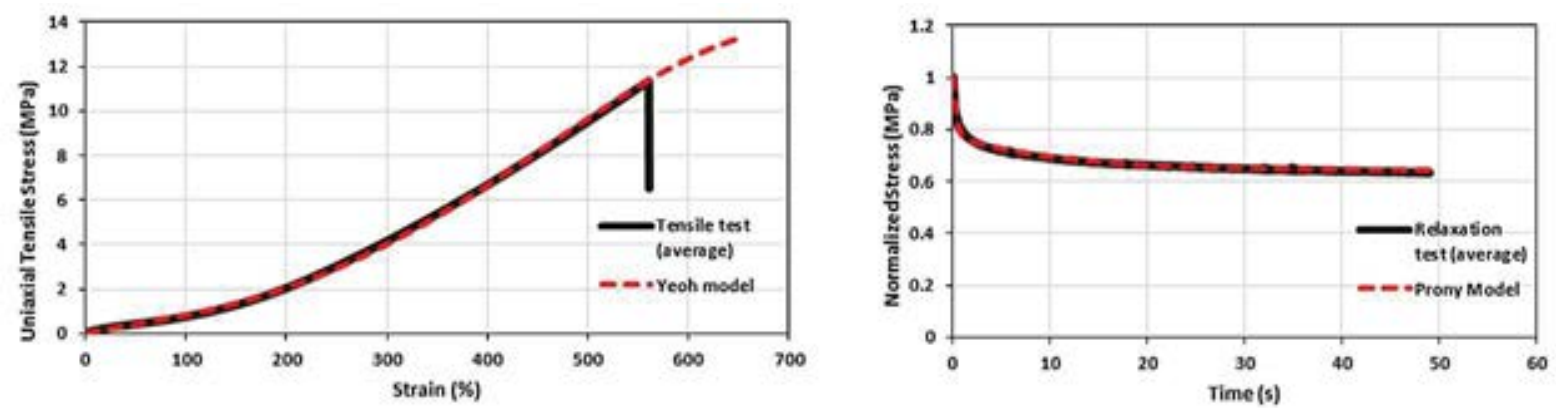

Figure 9: Calibration of elastomer constitutive parameters implemented in the finite element model of HDRB: hyperelastic Yeoh model (left), and Prony series (right).

\subsection{Results}

Fig. 10 compares the horizontal force - displacement curves predicted by the numerical code to the experimental curves obtained in the tests on full scale HDRBs. By considering the third cycle of loading, the agreement is fair for both the tests at $N=1150 \mathrm{kN}$ and $N=530 \mathrm{kN}$, while at $N=2230 \mathrm{kN}$ the numerical model is capable to correctly reproduce the loading branch of the curve, but underestimates the actual damping and the dissipation capability of the isolator.

The effective stiffness and equivalent viscous damping factor calculated in the numerical analyses are eventually compared to the experimental values in Table 3 . The numerical model calculates a decrease in stiffness when the axial load is increased from $N_{s d}$ to $2 N_{s d}$, but $k_{e f f}$ does not change substantially when the axial load is reduced to $0.5 N_{s d}$. The accuracy of the numerical prediction is good as concern the stiffness ( $8 \%$ deviation at $2 N_{s d}$ ), but the model underestimates the actual damping capacity of the isolators and is not able to capture the increase in viscous damping when $N$ passes from $N_{s d}$ to $2 N_{s d}(30 \%$ deviation).

(a)

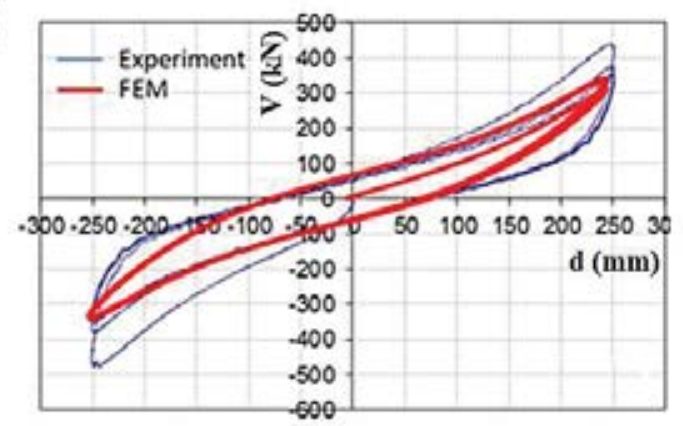

(b)

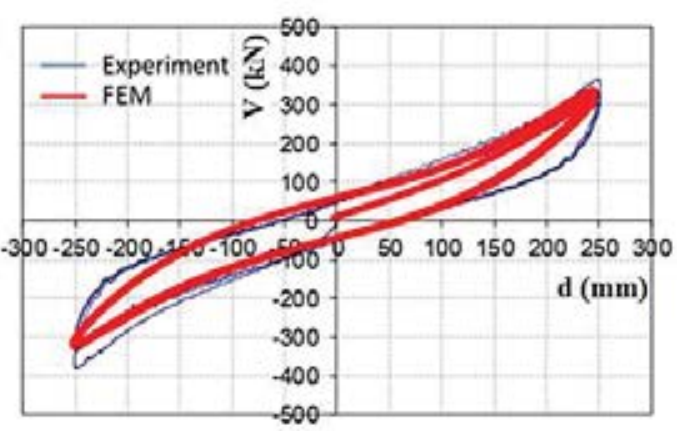

(c)

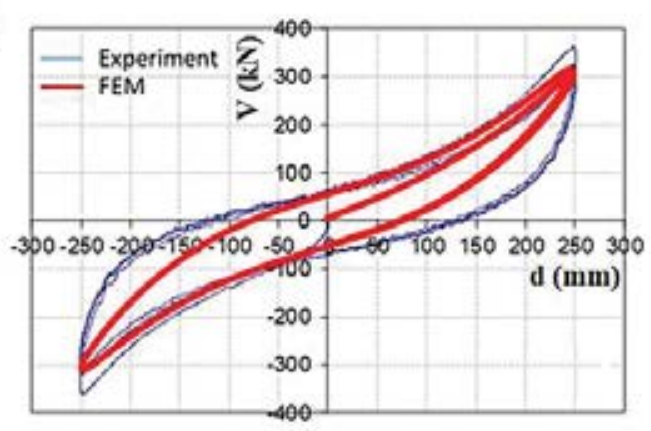

Figure 10: Comparison between experimental and numerical (FEM) force - displacement curves of the HDRB isolator at different levels of axial load: (a) $N=1150 \mathrm{kN}$; (b) $N=530 \mathrm{kN}$; (c) $N=2300 \mathrm{kN}$. 


\begin{tabular}{c|ll|ll}
\hline \multirow{2}{*}{$N(\mathrm{kN})$} & \multicolumn{2}{|l|}{$k_{\text {eff }}(\mathrm{kN} / \mathrm{mm})$} & \multicolumn{2}{l}{$\xi(\%)$} \\
& EXP & FEM & EXP & FEM \\
\hline 1150 & 1.36 & 1.36 & 10.40 & 9.17 \\
530 & 1.25 & 1.32 & 9.95 & 8.33 \\
2300 & 1.16 & 1.26 & 12.95 & 9.03 \\
\hline
\end{tabular}

Table 3: Experimental (EXP) and numerical (FEM) values of effective stiffness and equivalent viscous damping factor at different levels of axial load.

\section{DISCUSSION}

The study presents three different approaches to investigate the influence of the axial load on the properties in shear of HDRBs.

Experiments on small scale test pieces are rather cheap; indeed, the specimens are small and easy to manufacture, and a wide range of combinations of axial load and horizontal displacement can be tested at an affordable cost. Owing to the small size of the specimens, heating of the elastomer is expected to be small. Consistent results were obtained in the test campaign illustrated in this paper. However scaling effect may limit the accuracy of the extrapolation of the results to the real scale.

Tests on full scale isolators are expensive because require dedicated facilities and because the specimens are large and bulky. Moreover, heating of the isolator and its effect on the shear response may be not negligible in tests involving large energy inputs. Therefore in designing the experimental protocol an appropriate dwell time after each test must be envisaged in order to allow cooling of the specimens. However, since the tests are performed at the real scale, the results can be directly transferred to the application.

Numerical analyses allow to investigate many loading scenarios at a very limited cost, but the numerical model needs to be validated against experimental data to provide reliable results. Whereas accurate hyperelastic models are available to capture the actual stress - strain relationship of standard rubber, the viscous behavior of elastomeric compounds has not yet been effectively implemented into numerical codes.

\section{CONCLUSIONS}

The characterization of the effects of the axial load on the properties in shear of HDRBs is fundamental for developing accurate analyses and design of base isolation systems.

Examples of experimental and numerical approaches to investigate this subject have been presented in the paper. Whereas testing of small scale pieces is convenient at the stage of development and characterization of new rubber compounds, numerical analyses and testing of full scale isolators are most indicated at the final stage of design and validation of isolators for the real application.

Both small scale and large scale tests evidence that the axial load has a more substantial influence on the equivalent viscous damping than on the shear modulus of the elastomer. The numerical analyses demonstrate that the vertical - horizontal coupling of HDRBs can be deducted with a sufficient reliability from the characteristics of the elastomer measured in simple uniaxial tests, though more consistent models for viscous damping need to be formulated. 


\section{REFERENCES}

[1] F. Naeim, J.M. Kelly, Design of Seismic Isolated Structures, Wiley, 1999.

[2] M.C. Constantinou, A.S. Whittaker, Y. Kalpakidis, D.M. Fenz, G.P. Warn, Performance of Seismic Isolation Hardware under Service and Seismic Loading. Technical Report MCEER-07-0012, 2007.

[3] Y. Itoh, H. Gu, K. Satoh, Y. Yamamoto, Experimental investigation on ageing behaviors of rubbers used for bridge bearings. Structural Engineering / Earthquake Engineering, JSCE, 23(1), 17s-31s, 2006.

[4] A.C.T. Thompson, A.S. Whittaker, G.L. Fenves, S.A. Mahin, Property modification factors for elastomeric seismic isolation bearings. The $14^{\text {th }}$ World Conference on Earthquake Engineering (WCEE), October 12-17, Beijing, China, 2000.

[5] CEN (European Committee for Standardisation), EN15129 - Anti-seismic Devices, 2009.

[6] D. Cardone, G. Gesualdi, D. Nigro, Effects of air temperature on the cyclic behavior of elastomeric seismic isolators. Bulletin of Earthquake Engineering, 9(4), 1227-1255, 2011.

[7] V. Quaglini, P. Dubini, G. Vazzana, Experimental assessment of High Damping Rubber under combined compression and shear. ASME Journal of Engineering Materials and Technology, 138, 0110021-9, 2016.

[8] I.D. Aiken, J.M. Kelly, P.W. Clark, K. Tamura, M. Kikuchi, T. Itoh, Experimental studies of the mechanical characteristics of three types of seismic isolation bearings. $10^{\text {th }}$ World Conference on Earthquake Engineering (WCEE). July 19-24, Madrid, Spain, 1992.

[9] J.M. Kelly, Earthquake-resistant design with rubber, Springer-Verlag, London, UK, 1993.

[10] T. Mori, P.J. Moss, N. Cooke, A.J. Carr, The Behavior Of Bearings Used For Seismic Isolators Under Shear And Axial Load. Earthquake Spectra, 15(2), 199-224, 1999.

[11] M. Iizuka, A Macroscopic Model For Predicting Large-Deformation Behaviors Of Laminated Rubber Bearings. Engineering Structures, 22(4), 323-334, 2000.

[12] K.L. Ryan, J.M. Kelly, A.K. Chopra, Experimental observation of axial load effects in isolation bearings. ASME Journal of Engineering Mechanics, 131(12), 1270-1278, 2005.

[13] S.L. Burtscher, L.A. Dorfmann, Compression and shear tests of anisotropic high damping rubber bearings. Engineering Structures, 26(13):1979-1991, 2004.

[14] G.M. Montuori, E. Mele, G. Marrazzo, G. Brandonisio, A. De Luca, Stability issues and pressure-shear interaction in elastomeric bearings: the primary role of the secondary shape factor. Bulletin of Earthquake Engineering, 14:569-597, 2016.

[15] O.H. Yeoh, Some forms of the strain energy function for rubber. Rubber Chemistry and Technology, 66(5), 754-771, 1993.

[16] A.B. Habieb, G. Milani, V. Quaglini, F. Milani, Experimentation and numerical modelling of recycled rubber pads for seismic isolation under accelerated ageing. The $7^{\text {th }}$ International Conference on Computational Methods in Structural Dynamics and Earthquake Engineering (COMPDYN), June 24-26, Crete, Greece, 2019. 